\title{
Biomarkers of cardiac function and outcome in univentricular congenital heart disease
}

This article was published in the following Dove Press journal:

Current Biomarker Findings

3 June 2014

Number of times this article has been viewed

\section{Harold S Bernstein ${ }^{1,2}$ Hythem Nawaytou ${ }^{3}$}

'Merck Sharp \& Dohme Corp, Whitehouse Station, NJ, USA; ${ }^{2}$ The Mindich Child Health and Development Institute, Icahn School of Medicine at Mount Sinai, New York, NY, USA; ${ }^{3}$ Department of Pediatrics, University of California, San Francisco, CA, USA
Correspondence: Harold S Bernstein Merck Sharp \& Dohme Corp,

I 26 East Lincoln Avenue,

PO Box 2000, RY34-A500,

Rahway, NJ 07065-0900, USA

$\mathrm{Tel}+\mathrm{I} 7325942802$

Fax +I 7325942040

Email harold.bernstein@merck.com
Abstract: A biomarker is a clinical characteristic that predicts the presence of a specific physiological state, degree of severity of a pathophysiological state, or long-term outcome resulting from that state. Broadly defined, a biomarker can be a clinical parameter, or the result of a biochemical assay or imaging measure. Children are imperfect historians and cardiac disease may mimic other organ system diseases. Hence, reliable biomarkers can greatly enhance diagnosis and management of pediatric cardiac disease. In this review, we discuss the use of biomarkers in managing complex congenital heart disease characterized by single ventricle physiology.

Keywords: biomarker, natriuretic peptide, heart failure, congenital heart disease, single ventricle

\section{Introduction}

A biomarker is a measurable, surrogate characteristic that reflects the presence or severity of a disease state. A good clinical biomarker is one that is readily available, easily measured, and sensitive and specific for the disease state it is intended to inform upon. In the management of congenital heart disease, there is an urgent need for clinical biomarkers, since many pediatric patients cannot express their symptoms precisely, and the signs and symptoms of heart disease may overlap with those of other organ systems. In this review, we describe the use of biomarkers in situations in which they have shown utility in children and adolescents with univentricular congenital heart disease (Table 1). In these cases, biomarkers can differentiate between cardiac and non-cardiac causes of symptoms, guide management of these patients, and in some cases, predict outcomes for patients with this spectrum of complex cardiac lesions.

\section{Demographic and anatomic biomarkers associated with prognosis}

Patients with univentricular physiology are a growing population among those living with complex congenital heart disease. This can be attributed to major improvements in surgical technique, cardiac anesthesia, and postoperative and outpatient care. The spectrum of anatomical lesions resulting in this physiological state, and the various surgical options employed for palliation, make this group especially challenging to study. Biomarker data can be contradictory, making general conclusions difficult.

With the complexity of these patients in mind, however, certain patient characteristics, such as the morphology of the systemic ventricle (right, left, or primitive), the 


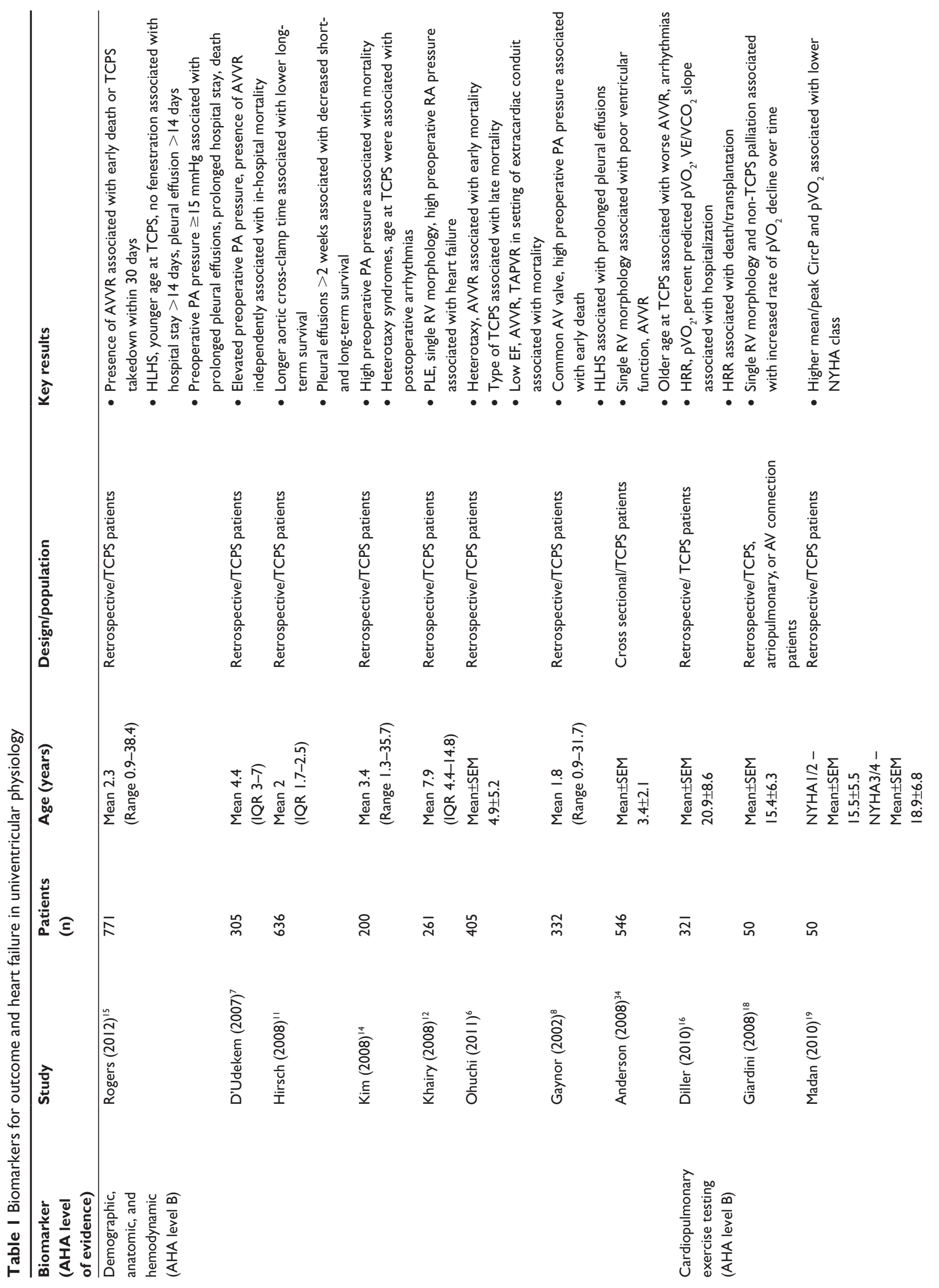



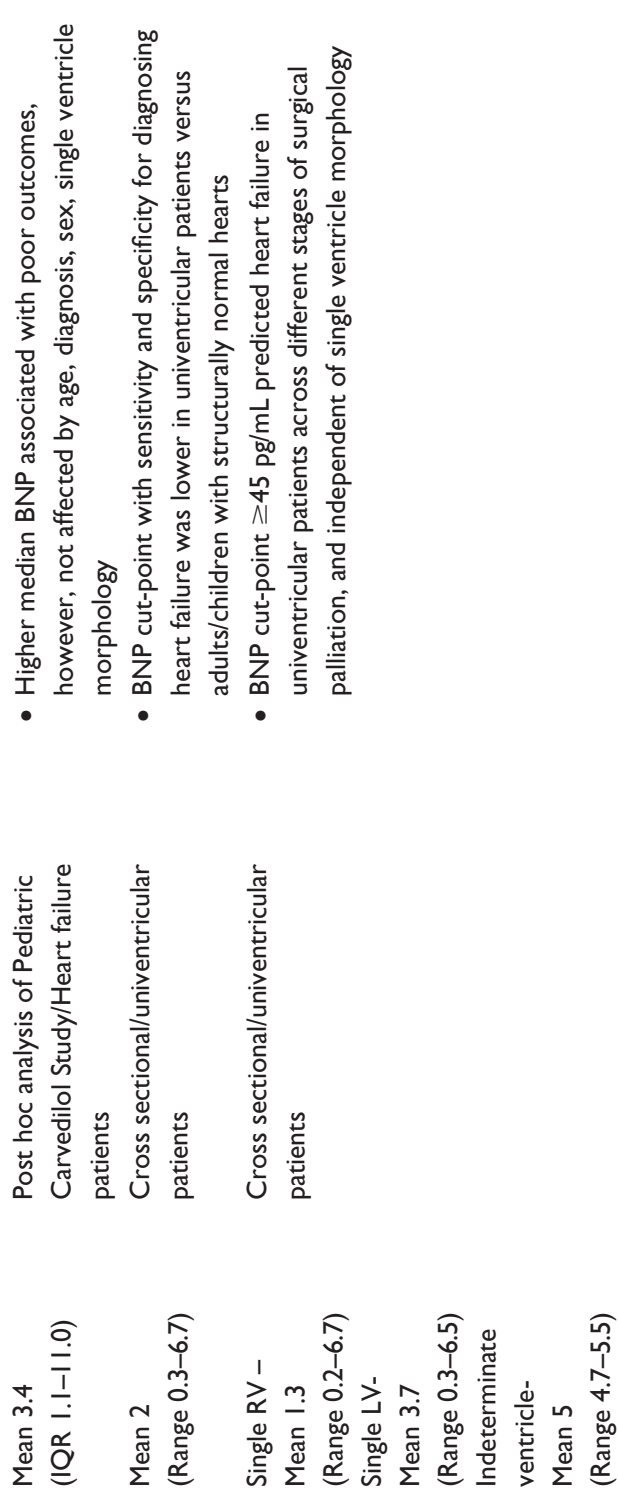

$\stackrel{\infty}{m} \quad \stackrel{\text { กे }}{\pi}$

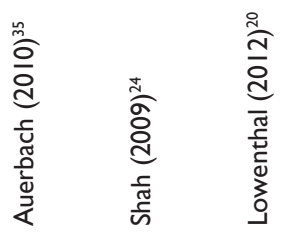

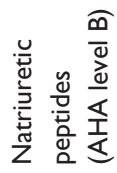

presence of a heterotaxy syndrome (ie, asplenia, polysplenia, ambiguous), and the type of surgery performed, places patients at different levels of risk. One study has shown that between the first two stages of palliation and in the presence of no or mild postoperative atrioventricular valve (AV) regurgitation, mortality is independently associated with gestational age less than 37 weeks, Hispanic ethnicity, aortic atresia/mitral atresia, greater number of post-Norwood complications, census block poverty level between $5.4 \%$ and $13 \%$, and modified Blalock-Taussig shunt. ${ }^{2}$ Thus, patients with any of the above characteristics should be observed more closely.

\section{Hemodynamic biomarkers associated with surgical outcome}

Multivariable risk analysis of 5 year follow-up data in patients with partial cavopulmonary shunt (PCPS; commonly referred to as a Glenn shunt) surgery showed greater than mild AV regurgitation, prolonged hospitalization after stage 1 palliation (eg, Norwood), and age $\leq 3$ months at PCPS to be independent risk factors for death or transplantation. ${ }^{3}$ At least moderate $\mathrm{AV}$ regurgitation and age $\leq 3$ months at PCPS was also an independent risk factor for not proceeding to total cavopulmonary shunt (TCPS; commonly referred to as Fontan) completion. ${ }^{3}$ These authors point out, however, that patients who underwent PCPS at an earlier age may have been less stable after stage 1 palliation, requiring earlier progress to stage 2 . In another study by Lee et al, moderate or severe AV regurgitation was acknowledged as a risk factor for survival to TCPS, but the presence of moderate ventricular dysfunction and an unbalanced atrioventricular canal defect were additional risk factors. ${ }^{4}$ In the same study, hypoxemia after PCPS that remained unexplained after cardiac catheterization carried an $80 \%-90 \%$ mortality rate. ${ }^{4}$

In univentricular physiology, integrity of AV valve function is critical to optimal function of a circulation in series, the goal of TCPS surgery. Presence of moderate or severe $\mathrm{AV}$ regurgitation is an established biomarker for higher mortality risk in TCPS patients. ${ }^{5}$ In a thirty year follow-up of TCPS patients, Ohuchi et al showed that presence of moderate or worse AV regurgitation, total anomalous pulmonary venous connection requiring repair, or ventricular ejection fraction $<58 \%$ were all associated with higher mortality. ${ }^{6}$ These authors also showed that the impact of heterotaxy syndrome on mortality decreased with surgical era and type of TCPS operation, losing its significance with the introduction of the extracardiac conduit. ${ }^{6}$ These data are concordant with those discussed by Kim et al, in which 
presence of a common AV canal was also found to increase the mortality risk after TCPS surgery. ${ }^{7,8}$ Whether heterotaxy patients are at higher risk because they experience higher incidence of regurgitation from the common AV valve as well as total anomalous pulmonary venous connection, or whether it is inherent in the syndrome is not known. However, outcomes for this group of patients have improved over the years, ${ }^{9}$ and the functional status of survivors is now similar to that of other univentricular patients without heterotaxy. ${ }^{10}$

The presence of a pleural effusion for more than two weeks after TCPS also has been associated with higher long-term mortality and development of protein-losing enteropathy. Protein-losing enteropathy was also more common in patients with a single morphologically right ventricle, ${ }^{11}$ and is an independent predictor of heart failure, death and TCPS failure. ${ }^{12,13}$ Patients with hypoplastic left heart syndrome are at increased risk for developing persistent pleural effusion, while presence of a fenestration in a lateral tunnel conduit at TCPS, or using modified ultrafiltration, decreased the risk of pleural effusion, duration of hospitalization, and death in this population. ${ }^{8}$

High right atrial pressures ${ }^{12}$ and elevated preoperative pulmonary artery pressure ${ }^{7,8,14}$ have been shown to be risk factors for death over the course of staged surgical palliation. Preoperative pulmonary artery pressure greater than $15 \mathrm{mmHg}$ was $90 \%$ specific for unfavorable outcome (hospital stay more than 14 days, pleural effusions lasting longer than 14 days, death prior to discharge) although with low sensitivity. ${ }^{15}$

Because the managing cardiologist should be aware of biomarkers of poor prognosis in specific patients, Diller et al devised a simple scoring system based on the risk factors of mortality, cardiac transplantation, and cardiac-related hospitalizations in a cohort of 321 TCPS patients. The system assigns one point for each of the following criteria if present: atrio-pulmonary connection, history of clinically significant arrhythmia, history of signs and symptoms of heart failure necessitating diuretic therapy. Patients with three risk factors had a 3-year risk of death or transplantation exceeding $40 \%$, while patients with no risk factors had a 3-year freedom from death or transplantation of $100 \%$. The scoring system was also able to predict cardiac-related hospitalization, and was shown to have predictive power superior to that of cardiopulmonary exercise testing. ${ }^{16}$

\section{Biomarkers of long-term outcome derived from exercise physiology}

Cardiopulmonary exercise testing (CPET) provides quantifiable measures of patient exercise (and functional) capacity.
Diller et al showed that peak oxygen consumption $\left(\mathrm{pVO}_{2}\right)$, percent predicted $\mathrm{pVO}_{2}$, anaerobic threshold, minute ventilation-carbon dioxide $\left(\mathrm{VE} / \mathrm{VCO}_{2}\right)$ slope, and heart rate reserve were all strongly predictive of cardiac-related hospitalization in univentricular physiology. However, only heart rate reserve predicted both death and cardiac transplantation. ${ }^{16}$ In this study, $81 \%$ of patients had a single morphologically left ventricle. Since patients with single left ventricle have more favorable results on CPET, ${ }^{17}$ and exhibit slower rates of decline over time, the predominance of left univentricular physiology in the study may have obscured a relationship between other parameters of CPET (eg, $\mathrm{pVO}_{2}, \mathrm{VE} / \mathrm{VCO}_{2}$ slope) and mortality or cardiac transplantation. ${ }^{18}$

Peak circulatory power ( $\mathrm{CircP})$, the product of $\mathrm{pVO}_{2}$ and peak systolic arterial blood pressure, and mean CircP, the product of $\mathrm{pVO}_{2}$ and mean systolic arterial blood pressure, have been implicated as outcome biomarkers in univentricular heart disease. In a cohort of 50 single ventricle patients, a cut-point of mean CircP $<2100 \mathrm{mmHg} / \mathrm{mL} \mathrm{O}_{2} / \mathrm{kg} / \mathrm{min}$ predicted a poorly functioning TCPS (NYHA class III-IV, protein-losing enteropathy, arrhythmias, death or transplantation) with $85 \%$ sensitivity. ${ }^{19}$

\section{Plasma biomarkers}

Plasma proteins traditionally come to mind when considering the topic of biomarkers, since these tend to be easier and less costly to obtain, measure, and standardize across clinical sites than biomarkers requiring invasive testing, imaging, or an exercise physiology lab. The use of plasma natriuretic peptide levels as biomarkers in univentricular patients, however, is controversial. B-type natriuretic peptide (BNP) is a peptide hormone produced in response to ventricular wall stress. ${ }^{20}$ It is rapidly cleared from the circulation through a process of cell surface binding and internalization, with a half-life of 20 minutes. ${ }^{20}$ BNP was analyzed in 510 outpatients after TCPS in a NHLBI Pediatric Heart Network study. ${ }^{21}$ After controlling for age, gender, and type of TCPS, investigators found that higher BNP levels had a weak positive correlation with preoperative systolic ventricular dysfunction, postoperative diastolic dysfunction, postoperative complications, including thrombosis, lower chronotropic index, and ventricular mass index above the 95th percentile based on cardiac magnetic resonance imaging. There was also a weak correlation between elevated BNP levels and poorer physical function summary and domain scores on the parent-completed Child Health Questionnaire. In this study, there was no correlation found between BNP level and presence or magnitude of AV regurgitation or morphology of 
the systemic ventricle. Based on their analysis, the authors concluded that outpatient monitoring of BNP in post-TCPS patients was not warranted.

Other investigators, however, have questioned this post hoc analysis, because of the inclusion of heterogeneous defects resulting in univentricular physiology, different surgical approaches employed, and varying management approaches used across centers. Koch et al demonstrated a correlation between BNP level and severity of AV regurgitation in patients with univentricular physiology and heart failure. ${ }^{22}$ BNP has also been shown to differentiate between isolated CPS (including both PCPS and TCPS) failure and ventricular dysfunction and/or AV regurgitation as causes of systemic congestion in this patient population. While elevations in $\mathrm{BNP}$ have not been detected in isolated CPS failure, increases in BNP level are observed with ventricular dysfunction and AV regurgitation. ${ }^{23}$

In two different studies, our group showed that doubling of BNP level in single ventricle patients was associated with a 2.2 odds ratio for heart failure ${ }^{20,24}$ as defined by a Ross score $\geq 3 .{ }^{25-27}$ A cut point of $\geq 45 \mathrm{pg} / \mathrm{mL}$ correctly classified $75 \%$ of single ventricle patients with respect to the presence of heart failure, with $62 \%$ sensitivity and $81 \%$ specificity. Univentricular patients with a morphologically right ventricle also demonstrated a cut-point of $\geq 45 \mathrm{pg} / \mathrm{mL}$ that correctly classified $76 \%$ of patients ( $71 \%$ sensitivity, $77 \%$ specificity). When stratified by stage, a cut-point of $45 \mathrm{pg} / \mathrm{mL}$ correctly classified $73 \%$ of stage I patients (100\% sensitivity, $60 \%$ specificity), $73 \%$ of stage II patients ( $57 \%$ sensitivity, $80 \%$ specificity), and $88 \%$ of stage III patients (100\% sensitivity, $83 \%$ specificity). This analysis supports a cut-point of $45 \mathrm{pg} / \mathrm{mL}$ for predicting heart failure in single right ventricle patients, regardless of stage of palliation. ${ }^{20}$

Since it is possible that univentricular patients produce less BNP precursor (pre-BNP), our group also examined whether N-terminal pro-BNP peptide (NT-proBNP), another product of pre-BNP processing cleared by renal excretion with a longer half-life (1-2 hours) ${ }^{28}$ was more useful for predicting heart failure in single ventricle patients. NT-proBNP is stable at room temperature for 72 hours, while BNP is stable for 24 hours, which also makes NT-proBNP a more stable biomarker target. ${ }^{29}$

We observed that for all patients with a single morphologically right ventricle, a cut-point of $\geq 1,100 \mathrm{pg} / \mathrm{mL}$ showed both sensitivity (78\%) and specificity (83\%), correctly classifying $82 \%$ of patients with respect to the presence of heart failure. Interestingly, when these patients were stratified by stage of surgical palliation, the threshold for classifying heart failure decreased with stage, which may reflect the gradual unloading of the single ventricle with successive procedures (ie, stabilization of pulmonary blood flow in stage 1 , followed by PCPS [stage 2], then TCPC [stage 3]). A cut-point of $1,900 \mathrm{pg} / \mathrm{mL}$ was needed to correctly classify $80 \%$ of patients at stage I, while this decreased to $1,100 \mathrm{pg} / \mathrm{mL}$ for stage II patients, and $300 \mathrm{pg} / \mathrm{mL}$ for stage III patients. ${ }^{20}$

These studies suggest that BNP and NT-proBNP can be useful in identifying patients at various stages of single ventricle palliation that have mild heart failure. This is supported by a recent systematic review of 16 published studies including 1,185 patients with univentricular heart disease..$^{30}$ This analysis concluded that elevated BNP levels were consistently elevated when patients were symptomatic, and there was a clear association between BNP level and NYHA functional class. Whether these biomarkers can be used to guide therapy in this patient population, however, remains to be demonstrated.

Beyond BNP, other plasma biomarkers are being evaluated that may be helpful in managing univentricular patients. Growth Differentiation Factor-15 level has been shown to correlate inversely with ejection fraction in univentricular patients, ${ }^{31} \mathrm{pVO}_{2}$ in adults with congenital heart disease, ${ }^{32}$ and directly with NT-ProBNP levels. ${ }^{32}$ A single nucleotide polymorphism (G5665T) in the preproendothelin-1 gene has also been identified as a potential biomarker for outcome in patients with hypoplastic left heart syndrome undergoing surgical palliation. ${ }^{33}$ Patients with the $\mathrm{T} / \mathrm{T}_{5665}$ genotype had significantly worse midterm prognoses with respect to transplant-free survival compared to patients with either $\mathrm{G} / \mathrm{T}_{5665}$ or $\mathrm{G} / \mathrm{G}_{5665}{ }^{33}$

\section{Conclusion}

In the field of complex congenital heart disease, biomarkers have significantly impacted patient management, from quantifying the degree of heart failure to identifying patients who are less likely to have a successful outcome with TCPS surgery and a univentricular circulation. While knowledge gaps remain, technological advances in molecular biology, biochemistry, and cell biology, as well as anatomic and metabolic imaging, and exercise testing, provide opportunities for new biomarkers to emerge. These will be essential not only to understanding the natural course of univentricular congenital heart disease with existing therapies, but to developing reasonable clinical trial strategies for testing new drugs that might limit thromboembolic complications and improve myocardial function in these patients. 


\section{Disclosure}

HS Bernstein is a current employee of Merck Sharp \& Dohme Corp, a subsidiary of Merck \& Co, Inc., and may own stock or hold stock options in the company.

\section{References}

1. American College of Cardiology Foundation and American Heart Association, Inc. Methodology Manual and Policies From the ACCF/ AHA Task Force on Practice Guidelines. Dallas, TX: ACC/AHA; 2010. Available from: http://assets.cardiosource.com/Methodology_Manual_ for_ACC_AHA_Writing_Committees.pdf. Accessed 27 May, 2014.

2. Ghanayem NS, Allen KR, Tabbutt S, et al. Interstage mortality after the Norwood procedure: Results of the multicenter Single Ventricle Reconstruction trial. J Thorac Cardiovasc Surg. Oct 2012;144(4): 896-906.

3. Friedman KG, Salvin JW, Wypij D, et al. Risk factors for failed staged palliation after bidirectional Glenn in infants who have undergone stage one palliation. Eur J Cardiothorac Surg. Oct 2011;40(4): 1000-1006.

4. Lee TM, Aiyagari R, Hirsch JC, Ohye RG, Bove EL, Devaney EJ. Risk factor analysis for second-stage palliation of single ventricle anatomy. Ann Thorac Surg. Feb 2012;93(2):614-618; discussion 619.

5. d'Udekem Y, Xu MY, Galati JC, et al. Predictors of survival after single-ventricle palliation: the impact of right ventricular dominance. J Am Coll Cardiol. March 27, 2012;59(13):1178-1185.

6. Ohuchi H, Kagisaki K, Miyazaki A, et al. Impact of the evolution of the Fontan operation on early and late mortality: a singlecenter experience of 405 patients over 3 decades. Ann Thorac Surg. Oct 2011;92(4):1457-1466.

7. d'Udekem Y, Iyengar AJ, Cochrane AD, et al. The Fontan procedure: contemporary techniques have improved long-term outcomes. Circulation. September 11, 2007;116(Suppl 11):I157-I164.

8. Gaynor JW, Bridges ND, Cohen MI, et al. Predictors of outcome after the Fontan operation: is hypoplastic left heart syndrome still a risk factor? J Thorac Cardiovasc Surg. Feb 2002;123(2):237-245.

9. Anagnostopoulos PV, Pearl JM, Octave C, et al. Improved current era outcomes in patients with heterotaxy syndromes. Eur J Cardiothorac Surg. May 2009;35(5):871-877; discussion 877-878.

10. Atz AM, Cohen MS, Sleeper LA, et al. Functional state of patients with heterotaxy syndrome following the Fontan operation. Cardiol Young. Sep 2007;17 Suppl 2:44-53.

11. Hirsch JC, Goldberg C, Bove EL, et al. Fontan operation in the current era: a 15-year single institution experience. Annals of surgery. Sep 2008;248(3):402-410.

12. Khairy P, Fernandes SM, Mayer JE Jr, et al. Long-term survival, modes of death, and predictors of mortality in patients with Fontan surgery. Circulation. January 1, 2008;117(1):85-92.

13. Mitchell ME, Ittenbach RF, Gaynor JW, Wernovsky G, Nicolson S, Spray TL. Intermediate outcomes after the Fontan procedure in the current era. J Thorac Cardiovasc Surg. Jan 2006;131(1): $172-180$.

14. Kim SJ, Kim WH, Lim HG, Lee JY. Outcome of 200 patients after an extracardiac Fontan procedure. J Thorac Cardiovasc Surg. Jul 2008;136(1):108-116.

15. Rogers LS, Glatz AC, Ravishankar C, et al. 18 years of the Fontan operation at a single institution: results from 771 consecutive patients. J Am Coll Cardiol. September 11, 2012;60(11):1018-1025.

16. Diller GP, Giardini A, Dimopoulos K, et al. Predictors of morbidity and mortality in contemporary Fontan patients: results from a multicenter study including cardiopulmonary exercise testing in 321 patients. Eur Heart J. Dec 2010;31(24):3073-3083.

17. Ohuchi H, Yasuda K, Hasegawa $\mathrm{S}$, et al. Influence of ventricular morphology on aerobic exercise capacity in patients after the Fontan operation. J Am Coll Cardiol. June 1, 2001;37(7):1967-1974.
18. Giardini A, Hager A, Pace Napoleone C, Picchio FM. Natural history of exercise capacity after the Fontan operation: a longitudinal study. Ann Thorac Surg. Mar 2008;85(3):818-821.

19. Madan N, Beachler L, Konstantinopoulos P, Worley S, Sun Z, Latson LA. Peak circulatory power as an indicator of clinical status in children after Fontan procedure. Pediatr Cardiol. Nov 2010;31(8):1203-1208.

20. Lowenthal A, Camacho BV, Lowenthal S, et al. Usefulness of B-type natriuretic Peptide and N-terminal pro-B-type natriuretic Peptide as biomarkers for heart failure in young children with single ventricle congenital heart disease. Am J Cardiol. March 15, 2012;109(6):866-872.

21. Atz AM, Zak V, Breitbart RE, et al. Factors associated with serum brain natriuretic peptide levels after the Fontan procedure. Congenit Heart Dis. Jul-Aug 2011;6(4):313-321.

22. Koch AM, Zink S, Singer H, Dittrich S. B-type natriuretic peptide levels in patients with functionally univentricular hearts after total cavopulmonary connection. Eur J Heart Fail. Jan 2008;10(1):60-62.

23. Law YM, Ettedgui J, Beerman L, Maisel A, Tofovic S. Comparison of plasma B-type natriuretic peptide levels in single ventricle patients with systemic ventricle heart failure versus isolated cavopulmonary failure. Am J Cardiol. August 15, 2006;98(4):520-524.

24. Shah A, Feraco AM, Harmon C, Tacy T, Fineman JR, Bernstein HS. Usefulness of various plasma biomarkers for diagnosis of heart failure in children with single ventricle physiology. Am J Cardiol. November 1, 2009;104(9):1280-1284.

25. Johnstone DE, Abdulla A, Arnold JM, et al. Diagnosis and management of heart failure. Canadian Cardiovascular Society. Can J Cardiol. Jul-Aug 1994;10(6):613-631, 635-654.

26. Rosenthal D, Chrisant MR, Edens E, et al. International Society for Heart and Lung Transplantation: Practice guidelines for management of heart failure in children. J Heart Lung Transplant. Dec 2004;23(12):1313-1333.

27. Ross RD, Bollinger RO, Pinsky WW. Grading the severity of congestive heart failure in infants. Pediatr Cardiol. Apr 1992;13(2):72-75.

28. Mair J, Gerda F, Renate H, Ulmer H, Andrea G, Pachinger O. Head-to-head comparison of B-type natriuretic peptide (BNP) and NT-proBNP in daily clinical practice. Int J Cardiol. February 29, 2008;124(2):244-246.

29. Dasgupta A, Chow L, Tso G, Nazareno L. Stability of NT-proBNP in serum specimens collected in Becton Dickinson Vacutainer (SST) tubes. Clin Chem. Jun 2003;49(6 Pt 1):958-960.

30. Eindhoven JA, van den Bosch AE, Jansen PR, Boersma E, Roos-Hesselink JW. The usefulness of brain natriuretic peptide in complex congenital heart disease: a systematic review. J Am Coll Cardiol. November 20, 2012;60(21):2140-2149.

31. Raedle-Hurst TM, Koenigstein K, Gruenhage F, Raedle J, Herrmann E, Abdul-Khaliq H. Growth differentiation factor 15 - an early marker of abnormal function of the Fontan circuit in patients with univentricular hearts. Am Heart J. Dec 2010;160(6):1105-1112.

32. Norozi K, Buchhorn R, Yasin A, et al. Growth differentiation factor 15 : an additional diagnostic tool for the risk stratification of developing heart failure in patients with operated congenital heart defects? Am Heart J. Jul 2011;162(1):131-135.

33. Kirshbom PM, Mahle WT, Joyner RW, et al. The endothelin-1 G5665T polymorphism impacts transplant-free survival for single ventricle patients. J Thorac Cardiovasc Surg. Jul 2008;136(1):117-122.

34. Anderson PA, Sleeper LA, Mahony L, et al. Contemporary outcomes after the Fontan procedure: a Pediatric Heart Network multicenter study. J Am Coll Cardiol. July 8, 2008;52(2):85-98.

35. Auerbach SR, Richmond ME, Lamour JM, et al. BNP levels predict outcome in pediatric heart failure patients: post hoc analysis of the Pediatric Carvedilol Trial. Circ Heart Fail. Sep 2010;3(5):606-611. 
Current Biomarker Findings

\section{Publish your work in this journal}

Current Biomarker Findings is an international, peer-reviewed, open access journal publishing original research, reports, reviews and commentaries on all areas of biomarker research. The manuscript management system is completely online and includes a very quick and fair

peer-review system. Visit http://www.dovepress.com/testimonials.php to read real quotes from published authors. 